\title{
SISTEMA DE INFORMAÇÕES GEORREFERENCIADAS PARA PROSPECÇÃO DE COBRE EM ROCHAS MÁFICAS E ULTRAMÁFICAS NO BLOCO VERMELHOS
}

\author{
Cândida Caroline Souza de Santana Leite'; Ardemírio de Barros Silva²; Washington de \\ Jesus Sant'Anna da Franca Rocha ${ }^{3}$ \\ 1. Bolsista PROBIC/Uefs, Graduando em Geografia, Universidade Estadual de Feira de Santana, e-mail: \\ candidaleite.geo@gmail.com \\ 2. Orientador, Departamento de Ciências Exatas, Universidade Estadual de Feira de Santana, e-mail: abarros@uefs.br \\ 3. Co-orientador, Departamento de Ciências Exatas, Universidade Estadual de Feira de Santana, e-mail: wrocha@uefs.br
}

\begin{abstract}
PALAVRAS-CHAVE: Pesquisa mineral; Sistema de Informação Georreferenciadas; Depósito de cobre.
\end{abstract}

\section{INTRODUÇÃO}

O Vale do Rio Curaçá (VRC) constitui um dos maiores distritos minerais de cobre do Brasil, com centenas de corpos máficos e ultramáficos, alguns deles, formando mineralizações econômicas sulfetadas de cobre, ocorrendo principalmente na forma de bornita e calcopirita (Teixeira et al, 2010). Conhecido desde o final do século 19 e explorado intensamente desde a década de 1980, a produção de cobre do principal depósito vem se exaurindo, sendo necessário a descoberta de novos depósitos para manutenção do parque industrial instalado na região.

A necessidade de aplicar tecnologias inovadoras para auxiliar a exploração mineral no VRC levou Ibanez \& Calachibete (2005) a realizarem um estudo do potencial mineral de cobre no local, em ambiente de Sistema de Informações Georreferenciadas (SIG), atestando a boa aplicação desta ferramenta para este tipo de estudo. Segundo os autores, o SIG dispõe de instrumentação adequada e eficiente para a elaboração de um banco de dados para suporte à pesquisa mineral. Um SIG consiste, de acordo com Silva (1999), em uma tecnologia que possui a instrumentação necessária para efetivar análises com dados espaciais.

O objetivo deste estudo consistiu na construção de um banco de dados em ambiente SIG reunindo dados geológicos digitais disponíveis e agregando novos dados produzidos por processamento digital em imagem de satélite do sensor Rapid Eye, com maior resolução espacial, a fim de contribuir na avaliação do potencial para mineralização de cobre no VRC, tendo com área de estudo o prospecto Vermelhos.

\section{METODOLOGIA}

- Modelo conceitual do depósito de Cobre

O prospecto Vermelhos, objeto de estudo desta pesquisa (figura 1), situa-se no município de Juazeiro (Bahia), entre as coordenadas UTM 379507E / 8992532N - 404492E / 8943467N, zona 24 Sul. 


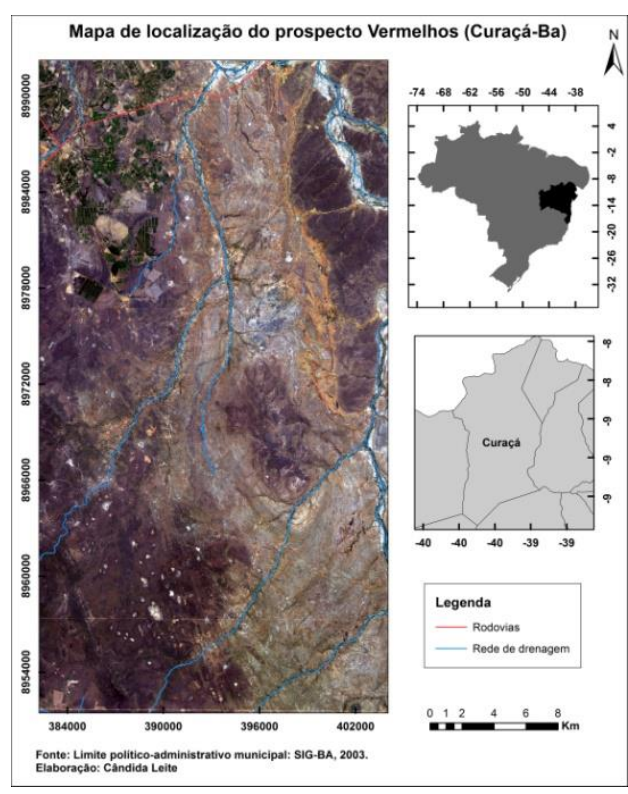

Figura 1: Mapa de localização da área de estudo.

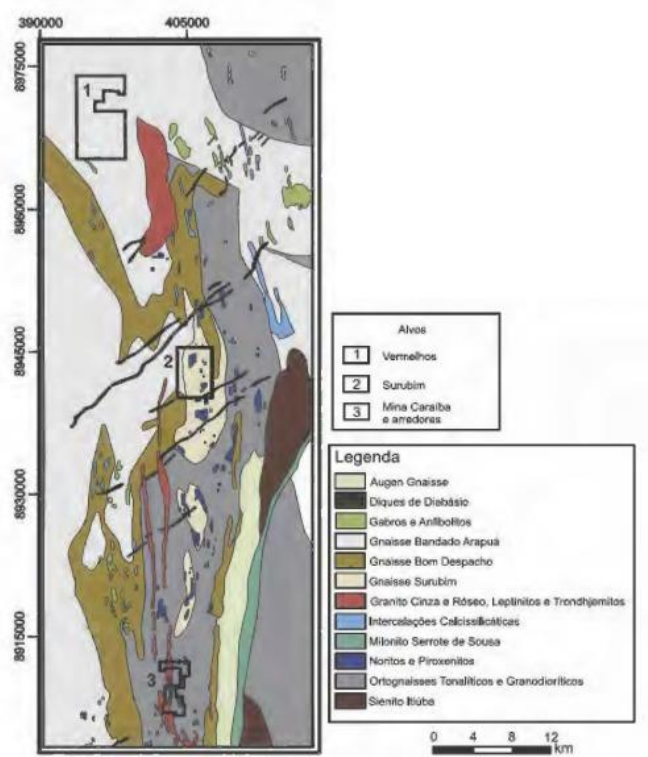

Figura 2: Mapa geológico simplificado.

A área estudada nesta pesquisa inclui o prospecto Vermelhos, composto por mineralizações econômicas de cobre, tendo por rochas encaixantes corpos máficos e ultramáficos. Segundo Teixeira et al (2010), esses corpos são cumulatos ultramáficos e máficos, presentes em Gnaisses bandados do tipo Arapuã como mostra o mapa geológico simplificado (figura 2), abundantes respectivamente em piroxenito e norito (melanorito e gabro norito).

Nesta área os sulfetos são constantemente acompanhados de magnetita, principalmente em áreas de concentração de sulfetos tectonocontrolados, onde o percentual de magnetita equipara-se ao percentual de sulfetos e às vezes o supera (Teixeira et al, 2010). Portanto, os corpos mineralizados desta área apresentam características espectrais de hidróxidos de ferro e de magnésio, assim como de óxido de ferro, presentes, aparentemente, no mineral biotita.

- Aquisição e processamento de dados

Para aquisição dos dados espectrais, assim como para o reconhecimento da área de estudo, foi realizado trabalho de campo entre os dias 23 e 26 de outubro de 2015, com coleta de amostras de rocha. No Laboratório de Espectrorradiometria da Universidade Estadual de Feira de Santana (UEFS) foram realizadas as medidas espectrais das amostras com o espectrorradiômetro FieldSpec 4 Hi-Res, sendo utilizado o acessório sonda de contato.

O processamento digital foi realizado em imagens RapidEye, de resolução espacial de 5 metros, com data de passagem em 16 de Julho de 2013, sendo necessário realizar o mosaico de duas imagens de satélite para abranger toda a área do prospecto. Considerando o padrão de associação mineralógica do depósito, revelado pelo seu modelo conceitual, obteve-se uma biblioteca espectral especifica com os dados espectrais medidos na etapa anterior, utilizando-a como base para o cálculo de um índice espectral de minerais de óxidos/hidróxidos de ferro. Esse índice espectral foi obtido pela técnica de Razão de Bandas (RB), que consiste em uma operação aritmética, na qual se divide a banda com o pico máximo de reflectância pela banda com o pico mínimo de reflectância.

Todas as etapas de processamento e análise dos dados foram efetuadas nas plataformas Envi 5.1 e ArcGis 10.1.

\section{ANÁLISE E DISCUSSÃO DOS RESULTADOS}

De acordo com Santos \& Franca-Rocha (2015), uma Biblioteca Espectral constitui-se a partir de um conjunto de curvas que definem o comportamento dos alvos estudados. Dessa 
forma, a Espectrorradiometria de reflectância tem grande aplicabilidade na caracterização de materiais, tais como, solos, rochas e minerais.

A Biblioteca Espectral gerada nesta pesquisa traz dados importantes acerca das características do depósito de cobre estudado, visto que possibilita identificar os tipos de materiais existentes nos pontos de medição. A figura 3 representa a assinatura espectral dos alvos estudados.

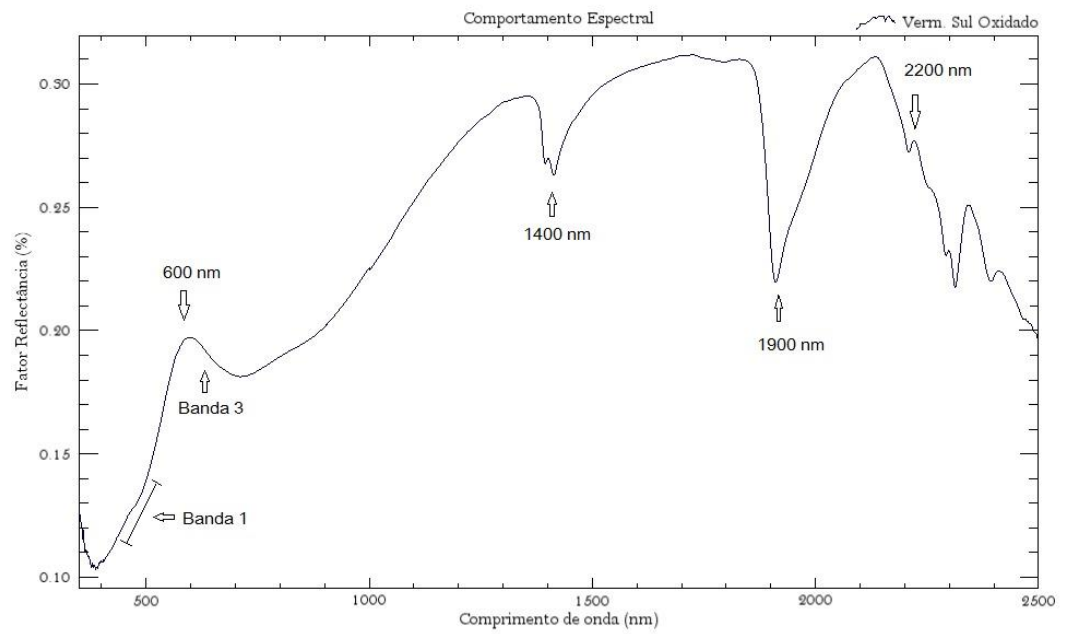

Figura 3: Exemplo de comportamento espectral dos alvos no prospecto Vermelhos.

A Biblioteca Espectral construída deu suporte para a elaboração do mapa de índice de ferro (figura 4) da área estudada. O mapa de índice de ferro do prospecto Vermelhos foi construído com base na Razão de Bandas entre as bandas espectrais 3 e 1 do RapidEye, que possuem pico máximo em $610 \mathrm{~nm}$ e mínimo em $470 \mathrm{~nm}$.

Diversos estudos utilizam esta razão quando há minerais de ferro associados à mineralização, como é o caso dos depósitos de Cobre do Vale do Curaçá, pois, a partir dessa operação, constata-se o realce das feições de interesse, destacando o contraste nos diferentes materiais na imagem de satélite (Lima, 2011).

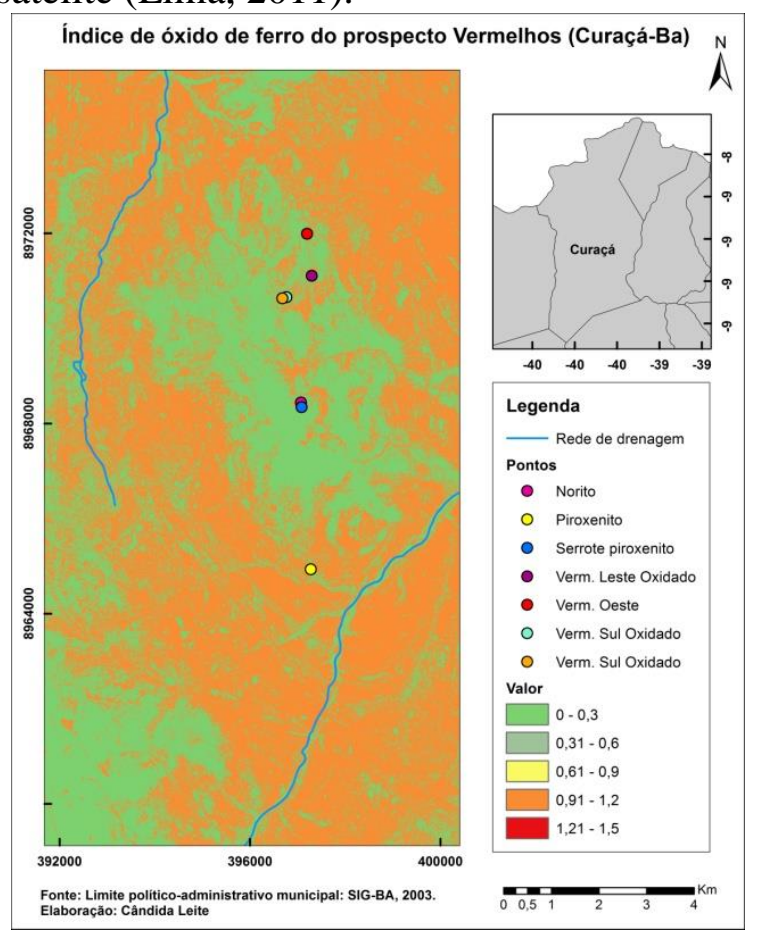

Figura 4: Mapa do índice de óxido de ferro encontrado no prospecto Vermelhos a partir do método Razão de bandas. 
Na imagem Índice de Ferro é possível observar as áreas de ocorrência de óxido de ferro, de modo que, em conjunto com a análise do comportamento espectral dos materiais estudados, observou-se que dos 7 pontos, apenas 1 deles (Vermelho Oeste) não se encontra em zona de ocorrência do minério. Da mesma forma, identifica-se ainda na imagem-índice muitas áreas com anomalias de óxidos de ferro (locais dentro do intervalo de 0,91-1,12), além dos pontos que foram coletados em campo.

\section{CONSIDERAÇÕES FINAIS}

No decorrer dessa pesquisa foram realizados procedimentos e análises baseados em tecnologias de Sensoriamento Remoto e SIG, com o propósito de criar um banco de dados para contribuir na exploração mineral de cobre no distrito de Vermelhos (Juazeiro) na região no Vale do Rio Curaçá.

A metodologia empregada foi eficaz, visto que possibilitou caracterizar feições espectrais de minerais de óxidos/hidróxidos de ferro em amostras obtidas em alguns alvos de sulfetos de cobre, permitindo a construção da biblioteca espectral e a elaboração dos mapas de índice de óxido de ferro para a área de estudo. Esses mapas apontam locais de maior concentração de minerais de ferro comumente associados aos depósitos de cobre, auxiliando na prospecção de novos depósitos.

\section{REFERÊNCIAS}

IBANEZ, D. M.; CALACHIBETE, C. Estudos do potencial mineral de cobre $(\mathrm{Cu})$ através de SIG na região do Vale do Rio Curaça-Ba. Anais... XII Simpósio Brasileiro de Sensoriamento Remoto. Goiânia, Brasil, 16-21 abril 2005, INPE, p. 1807-1814.

LIMA, K. dos P. R. A avaliação do uso de Imagens Landsat para a prospecção de minério tipo Itabirito, com baixo teor de ferro - O caso da Serra de Bom Sucesso, MG. 2011. 51 p. Monografia (Especialização em Geoprocessamento) - Instituto de Geociências, Universidade Federal de Minas Gerais, Belo Horizonte, 2011.

SANTOS, S. B. M. e FRANCA-ROCHA, W. de J. S. Biblioteca espectral de solos em uma área no município de Mucugê-Ba. In: XVII Simpósio Brasileiro de Sensoriamento Remoto, 2015, João Pessoa. Anais... João Pessoa: INPE, 2015. p. 6298-6304.

SILVA, A. B. Sistemas de Informações Geográficas: conceitos e fundamentos. Campinas, SP: Editora da Unicamp, 1999.

TEIXEIRA, J. B. G. et al. Depósitos de Cobre do Vale do Rio Curaçá, Bahia. In: BRITO, R. S. C. de; SILVA, M. da G. e KUYUMJIAN, R. M. (Ed.). Modelos de depósitos de Cobre do Brasil e sua resposta ao intemperismo. Brasília: CPRM, 2010. Cap. 4, p. 73-95. 